\title{
Narrow row spacing increased yield and decreased nicotine content in sun-cured tobacco (Nicotiana tabacum L.)
}

\author{
D.J. Bilalis a , I.S. Travlos ${ }^{\mathrm{a}, *}$, J. Portugal $^{\mathrm{b}}$, S. Tsioros ${ }^{\mathrm{a}}$, Y. Papastylianou ${ }^{\mathrm{a}}$, Y. Papatheohari ${ }^{\mathrm{a}}$, \\ C. Avgoulas ${ }^{\mathrm{a}}$, I. Tabaxi ${ }^{\mathrm{a}}$, E. Alexopoulou ${ }^{\mathrm{c}}$, P.J. Kanatas ${ }^{\mathrm{a}}$
}

a Laboratory of Agronomy, Faculty of Crop Science, Agricultural University of Athens, GR 11855, Greece

b Polytechnic Institute of Beja, School of Agriculture, Beja, Portugal

c Center for Renewable Energy Sources and Saving-CRES, Athens, Greece

\section{A R T I C L E I N F O}

\section{Article history:}

Received 11 January 2015

Received in revised form 22 May 2015

Accepted 24 May 2015

Available online 10 June 2015

\section{Keywords:}

Sun-cured tobacco

Nicotiana tabacum $\mathrm{L}$.

Row spacing

Yield

Quality

\begin{abstract}
A B S T R A C T
Sun-cured tobacco (Nicotiana tabacum) is one of the most important industrial crops for Greece and other Mediterranean countries. A field experiment was conducted in 2012 and 2013 under organic conditions in Agricultural University of Athens in order to compare the growth, yield, nicotine and sugar content of three Greek sun-cured tobacco cultivars at two between-row spacings. Three cultivars of the Greek Basmas were sown in a seedbed in a greenhouse and then transplanted in the field at distances 10-and $20-\mathrm{cm}$ between rows. The experimental design was a split-plot in a randomized complete block with three replicates. Tobacco was harvested at 80, 95, 115, and 135 days after transplanting (DAT). Our results showed that wider row spacing resulted in lower yield than closer row spacing for all three cultivars. Cultivars $\times$ year interaction was significant for total yield. Tobacco yield ranged from 1315 to 1920 and from 1545 to $2090 \mathrm{~kg} \mathrm{ha}^{-1}$, for the wider and narrower row spacing, respectively. Chemical analysis revealed that nicotine content was also affected by cultivar and row spacing and ranged between 3.40 and 5.19\%. Narrow row spacing resulted in reduction of nicotine content, while sugar content was only affected by cultivar. Narrower row spacing could be used in some cases for a higher production of tobacco of lower nicotine content, whenever this is desirable for blending purposes.
\end{abstract}

(c) 2015 Elsevier B.V. All rights reserved.

\section{Introduction}

Tobacco (Nicotiana tabacum L.) is one of the most important industrial crops for many countries (Akehurst, 1968; Rezitis and Brown, 1999). Especially, Eastern-type tobacco, with its Greek varieties, is of high quality, and it is a crop with further potential especially for marginal or declining areas (it accounts for more than $90 \%$ of the total area cultivated by tobacco-growers in Greece). In addition to the foreign currency which it brings in, tobacco plays a very important social and economic role, since it is the main source of income for many families, not to mention the people employed in processing and marketing the product (Bilalis et al., 2009; Rezitis and Brown, 1999). Thanks to the type of soil, which is particularly suitable, ideal climatic conditions and a long tradition for growing the product, Greek oriental tobacco is of high quality regarding color, aroma and flavor, and has excellent burning properties (Travlos et al., 2014).

\footnotetext{
* Corresponding author. Tel.:+30 2105294483.

E-mail addresses: travlos@aua.gr, htravlos@yahoo.gr (I.S. Travlos).
}

However, tobacco quality can be significantly modified by cultivar and growing practices (Tso, 1990). Among growing practices, plant spacing can affect agronomic and chemical traits of tobacco (Schlotzhauer et al., 1989). Plant spacing in tobacco production usually refers to distances between tobacco plants within and between rows in the field, but it can also be interpreted as total number of plants and leaves produced within a defined area (Bukan et al., 2010; Campbell et al., 1982). In most cases, narrower spacing of plants generally results in a reduction of size, body, thickness, and weight per unit area of the leaf (Lamprecht and Van der Merwe, 1984; Sfikas, 1970). At higher planting densities an increase of yield of some tobacco cultivars has been reported by several authors. However, quality of such leaves was within a wide range and consequently increasing plant population remains a challenge (Chaplin et al., 1968; Collins et al., 1969; Lamprecht and Van der Merwe, 1984).

In many cases, Greek farmers tend to prefer wide distances between rows, in order to produce bigger leaves. Therefore, the objective of the present study was to compare under organic conditions the growth, yield and nicotine and sugars content of three Greek sun-cured tobacco cultivars at two between-row spacings. 

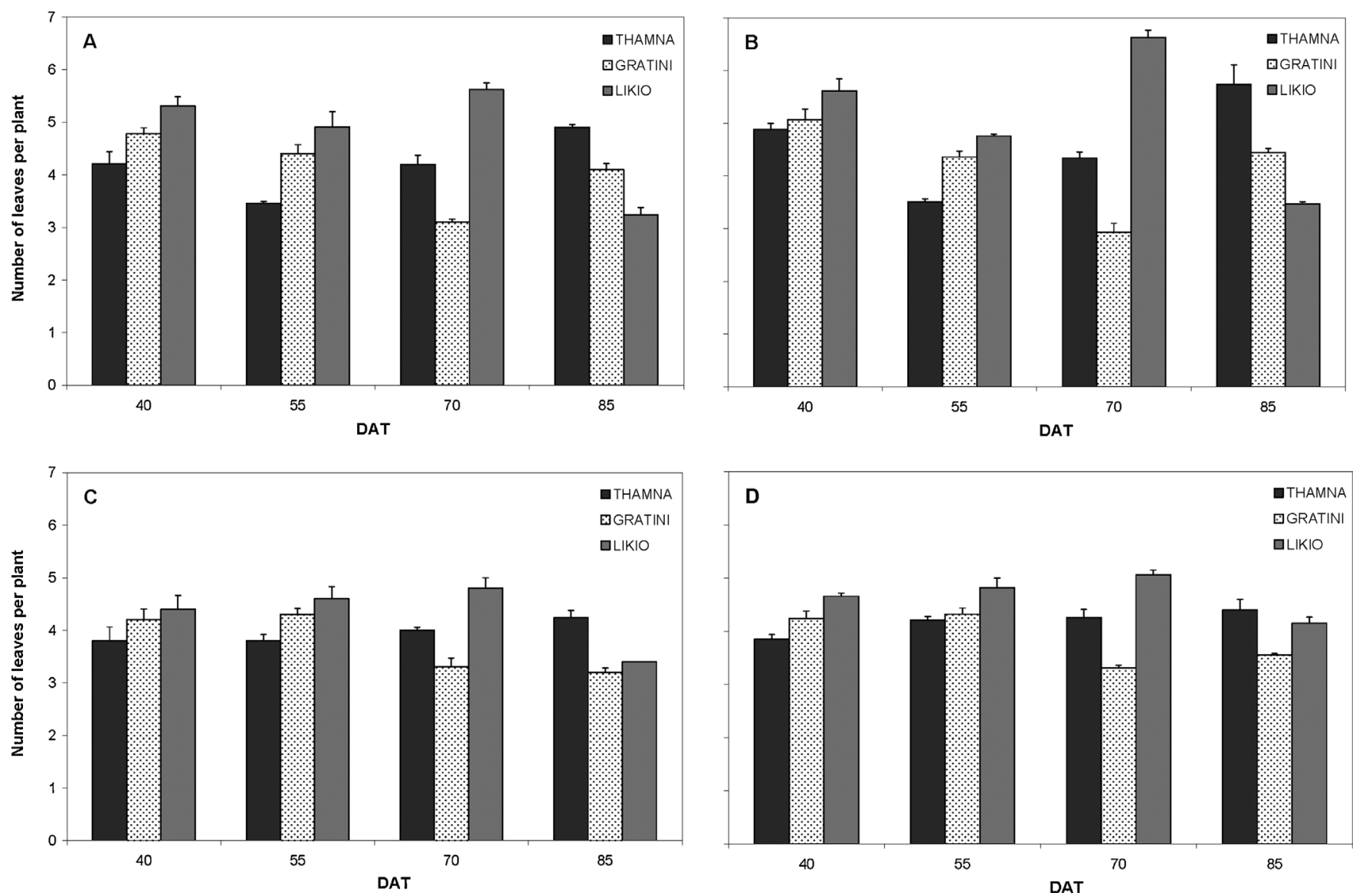

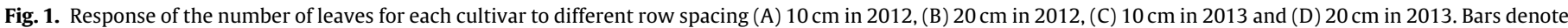
standard errors of the means.

Table 1

Mean monthly rainfall and temperature during the field experiments in 2012 and 2013.

\begin{tabular}{llclc}
\hline & \multicolumn{2}{l}{ Rainfall } & \multicolumn{2}{l}{ Temperature } \\
Month & 2012 & 2013 & 2012 & 2013 \\
\hline & ----- & mm & ----- & \multicolumn{2}{c}{$------{ }^{\circ}$ C -----} \\
March & 18.4 & 14.6 & 11.6 & 13.5 \\
April & 8.0 & 2.2 & 16.8 & 17.1 \\
May & 17.2 & 8.8 & 20.8 & 22.2 \\
June & 0.0 & 11.2 & 27.1 & 25.3 \\
July & 0.0 & 0.0 & 30.7 & 28.2 \\
August & 0.0 & 0.0 & 29.2 & 28.6 \\
September & 1.4 & 0.0 & 24.8 & 24.1 \\
October & 1.0 & 11.8 & 21.5 & 18.5 \\
\hline
\end{tabular}

\section{Materials and methods}

\subsection{Experimental details}

A field experiment was carried out in 2012 and 2013 under organic conditions in the experimental field of the Agricultural University of Athens ( $37^{\circ} 59^{\prime} 12 \mathrm{~N}, 23^{\circ} 42^{\prime} 96 \mathrm{E}, 29 \mathrm{~m}$ altitude). The soil was sandy clay loam $\left(520 \mathrm{~g} \mathrm{~kg}^{-1}\right.$ sand, $140 \mathrm{~g} \mathrm{~kg}^{-1}$ clay and $340 \mathrm{~g}$ $\mathrm{kg}^{-1}$ silt) (Bouyoucos, 1962), with $\mathrm{pH} 7.11\left(1: 2 \mathrm{H}_{2} \mathrm{O}\right), 19 \mathrm{~g} \mathrm{~kg}^{-1}$ organic matter (Wakley and Black, 1934), $134 \mathrm{~g} \mathrm{~kg}^{-1} \mathrm{CaCO}_{3}, 16 \mathrm{~g}$ $\mathrm{kg}^{-1}$ total nitrogen, a medium supply of available phosphorus (P-Olsen $0.021 \mathrm{~g} \mathrm{~kg}^{-1}$ ) and a good supply of available potassium $\left(0.8 \mathrm{~g} \mathrm{~kg}^{-1}\right)$. The crop cultivated both years before the tobacco was pea ( $P$. sativum cv. Arvika), which was incorporated into the soil with a disk harrow. Three cultivars of the Greek Basmas (orien-

\section{Table 2}

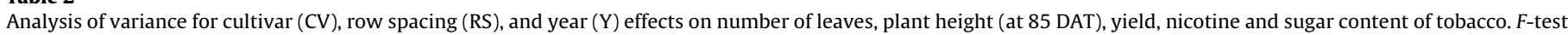
values are shown.

\begin{tabular}{|c|c|c|c|c|c|c|c|}
\hline Source & df & Number of leaves & Plant height & Total yield & Nicotine content & Sugar content & Sugar/nicotine ratic \\
\hline CV & 2 & $78.91^{* * *}$ & $69.74^{* * *}$ & $19.61^{* * * *}$ & $54.42^{* * *}$ & $29.62^{* * *}$ & $21.28^{* * *}$ \\
\hline RS & 1 & $26.67^{* *}$ & $30.74^{* * *}$ & $11.40^{* *}$ & $6.65^{*}$ & $0.75 \mathrm{~ns}$ & $1.04 \mathrm{~ns}$ \\
\hline $\mathrm{CV} \times \mathrm{RS}$ & 2 & $0.34 \mathrm{~ns}$ & $0.08 \mathrm{~ns}$ & $0.13 \mathrm{~ns}$ & $0.01 \mathrm{~ns}$ & $2.42 \mathrm{~ns}$ & $0.71 \mathrm{~ns}$ \\
\hline Y & 1 & $32.56^{* *}$ & $12.30^{* *}$ & $0.18 \mathrm{~ns}$ & $14.51^{* * *}$ & $2.64 \mathrm{~ns}$ & $14.80^{* * *}$ \\
\hline $\mathrm{Y} \times \mathrm{CV}$ & 2 & $28.11^{* * *}$ & $1.44 \mathrm{~ns}$ & $3.62^{*}$ & $6.25^{* *}$ & $1.17 \mathrm{~ns}$ & $5.87^{* *}$ \\
\hline $\mathrm{Y} \times \mathrm{RS}$ & 1 & $0.08 \mathrm{~ns}$ & $0.25 \mathrm{~ns}$ & $0.57 \mathrm{~ns}$ & $0.56 \mathrm{~ns}$ & $1.39 \mathrm{~ns}$ & $0.01 \mathrm{~ns}$ \\
\hline $\mathrm{Y} \times \mathrm{CV} \times \mathrm{RS}$ & 2 & $4.07^{*}$ & $0.22 \mathrm{~ns}$ & $0.96 \mathrm{~ns}$ & $0.16 \mathrm{~ns}$ & $0.36 \mathrm{~ns}$ & $0.48 \mathrm{~ns}$ \\
\hline
\end{tabular}

$$
\begin{array}{rl}
{ }^{*} & P<0.05 . \\
& { }^{* *} \quad P<0.01 .
\end{array}
$$

ns = not significant

${ }^{* * *} P<0.001$ 

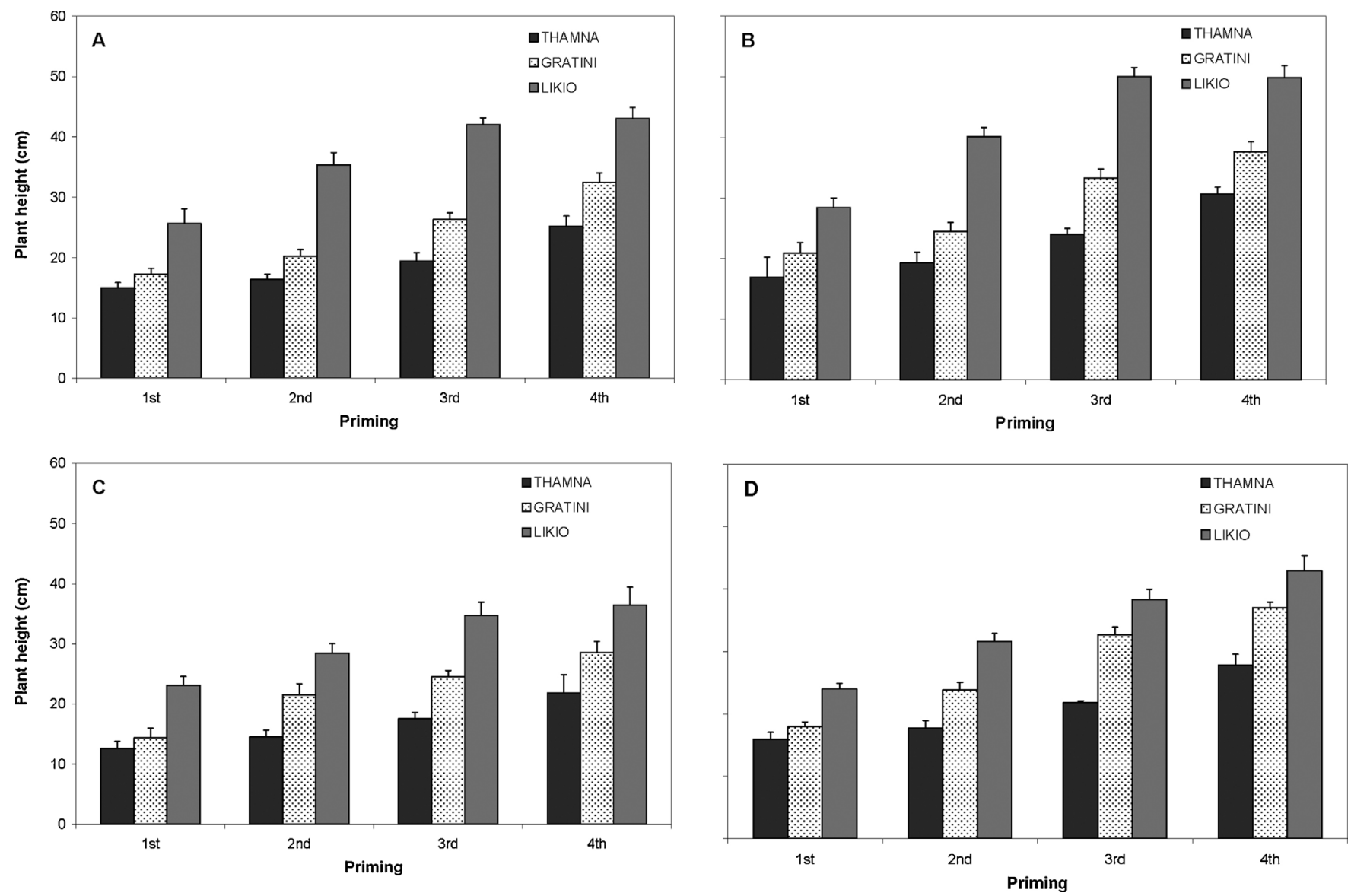

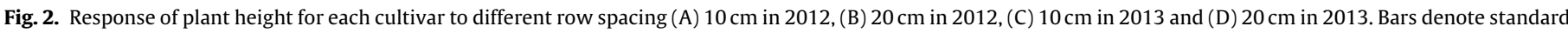
errors of the means.

Table 3

Sugar/nicotine ratios for the three tobacco cultivars at the different row spacings in 2012 and 2013.

\begin{tabular}{lllll}
\hline Cultivar & $\begin{array}{l}2012 \\
10 \mathrm{~cm}\end{array}$ & $20 \mathrm{~cm}$ & $\begin{array}{l}2013 \\
10 \mathrm{~cm}\end{array}$ & $20 \mathrm{~cm}$ \\
\hline Thamna & $0.978 \pm 0.027$ & $0.907 \pm 0.048$ & $0.927 \pm 0.068$ & $0.885 \pm 0.003$ \\
Gratini & $1.269 \pm 0.021$ & $1.154 \pm 0.024$ & $1.165 \pm 0.029$ & $1.110 \pm 0.040$ \\
Likio & $1.334 \pm 0.043$ & $1.415 \pm 0.185$ & $1.056 \pm 0.080$ & $1.023 \pm 0.007$ \\
\hline
\end{tabular}

Values are means \pm standard errors.

tal type), known as "Thamna", "Gratini" and "Likio" were sown in a seedbed in a greenhouse on 5 March 2012 and 25 February 2013. Transplanting of tobacco seedlings in the field was done on 9 May 2012 and 27 April 2013 at distances 10 and $20 \mathrm{~cm}$ between rows (Fig. 1), while within-row plant spacing was $30 \mathrm{~cm}$. Cultivation (hand hoeing) was carried out twice: at 10,20 and 30 days after transplanting (DAT). Irrigation was scheduled as recommended for this type of tobacco during both growing seasons (TIC, 1996) and fertilization was achieved by the incorporation of pea as green manure as previously described.

The experimental design was a split-plot in a randomized complete block with three replicates, three main plots (CV, cultivars) and two sub-plots (RS, row spacing of 10 and $20 \mathrm{~cm}$ ). The plot size was $5 \mathrm{~m} \times 2 \mathrm{~m}$ and the sub-plot size was $2 \mathrm{~m} \times 2 \mathrm{~m}$. The distance among plots was $1 \mathrm{~m}$ and the same distance was also kept among sub-plots and among replicates. Mean monthly temperature and rainfall data during the growing season as recorded in the Agricultural University of Athens are given in Table 1.

\subsection{Measurements and determinations}

Measurements of the number of leaves and plant height were taken at 40, 55, 70, 85 and 80, 90, 115 and 135 DAT, respectively, in 10 tobacco plants of the two middle rows of each sub-plot. Tobacco was harvested by hand, in four primings (at 80, 95, 115 and 135 DAT). In each cutting, the mature leaves (older) were harvested and properly sun-cured. Tobacco yield was the sum of the dry weights of each separate harvest. Samples from all the primings were combined to prepare composite samples, which were used for the chemical determinations. Samples were dried at $80^{\circ} \mathrm{C}$ for $72 \mathrm{~h}$, to constant dry weight, in a forced-air oven and ground in a Wiley mill using a $1 \mathrm{~mm}$ sieve. Nicotine and reducing sugars were measured using CORESTA recommended methods no.35 (ISO/DIS 15152) (CORESTA, 1994a) and no.38 (ISO/DIS 15154) (CORESTA, 1994b), respectively.

\subsection{Statistical analysis}

Analysis of variance (ANOVA) was conducted for all data. All statistical analyses were conducted using the Statistica 7 software package (StatSoft, Inc. 2300 East 14th Street, Tulsa, OK 74104, USA).

\section{Results and discussion}

Analysis of variance of our data revealed that the effect of cultivar was significant for all growth, yield and quality parameters. Number of leaves, plant height, yield and nicotine content were significantly affected by row spacing. The year was also a significant factor for all the measured parameters except yield. Moreover, 

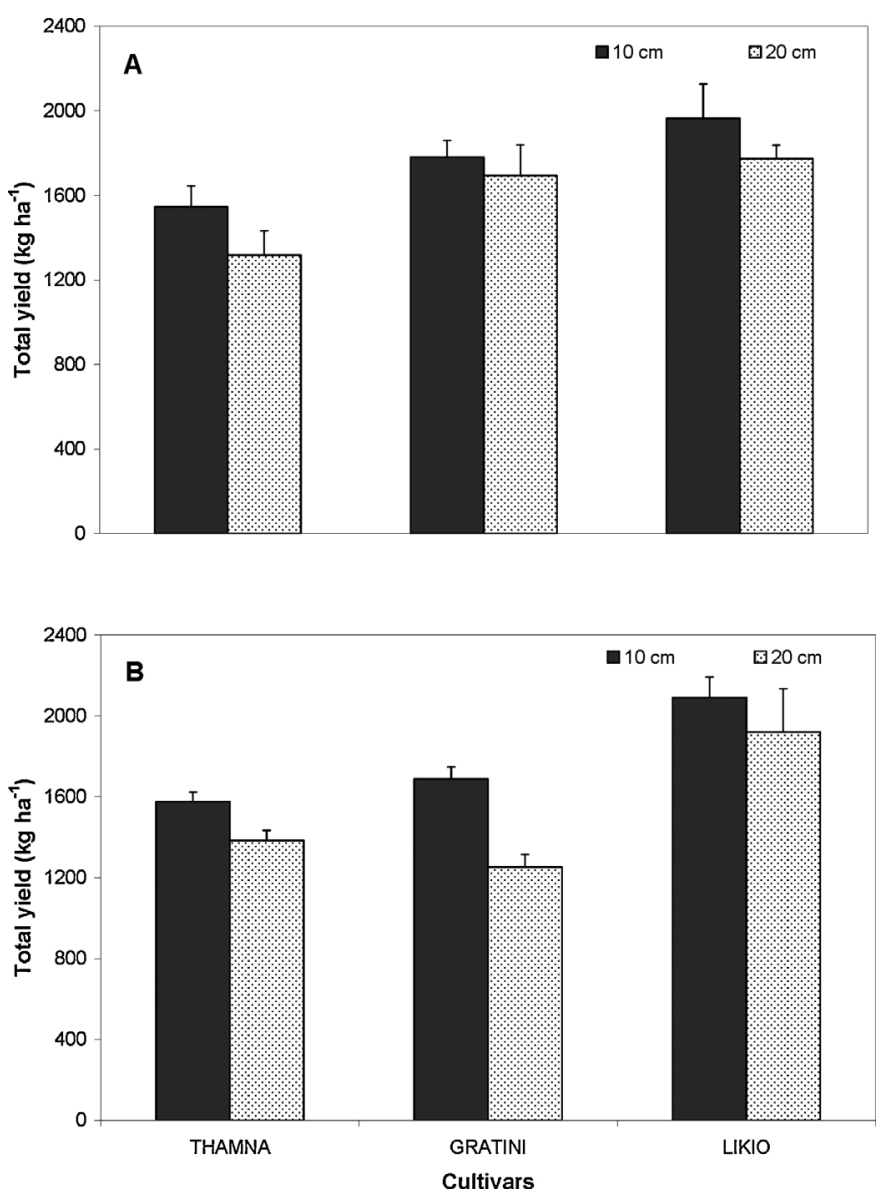

Fig. 3. Response of tobacco total yield for each cultivar to row spacing in (A) 2012 and (B) 2013. Bars denote standard errors of the means.

the interaction of the year with the cultivar was significant for the number of tobacco leaves, total yield, nicotine content and sugar/nicotine ratio, as well.

\subsection{Plant growth parameters}

The significant effects of cultivar, row spacing and year on tobacco growth and in particular on the number of leaves are shown in Fig. 1. Likio was the cultivar with the higher number of leaves at least until 70 DAT. Furthermore, wider spacing between rows resulted in more harvested leaves per plant for each harvest, probably due to the lower competition between tobacco plants (Fig. 1). These differences between the two row spacings were more intense during 2012.

Regarding plant height, the effects were quite similar, with Likio being the higher cultivar in all cases (Fig. 2). Moreover, row spacing of $20 \mathrm{~cm}$ resulted to $16-26 \%$ and $4-26 \%$ higher plants than the $10 \mathrm{~cm}$ row spacing for 2012 and 2013, respectively. It has also to be noted that some of the differences on tobacco growth during the two years may be related with the differences in the precipitation dispersal during the two growing seasons as shown in Table 1 . In all cases, the period of rapid growth was until 60 DAT, as previously mentioned in other studies (Lolas et al., 1983). It is also noticeable that all cultivars continued to grow after 60 DAT, which is in full accordance with previous studies on oriental tobacco grown in Greece (Lolas et al., 1983).
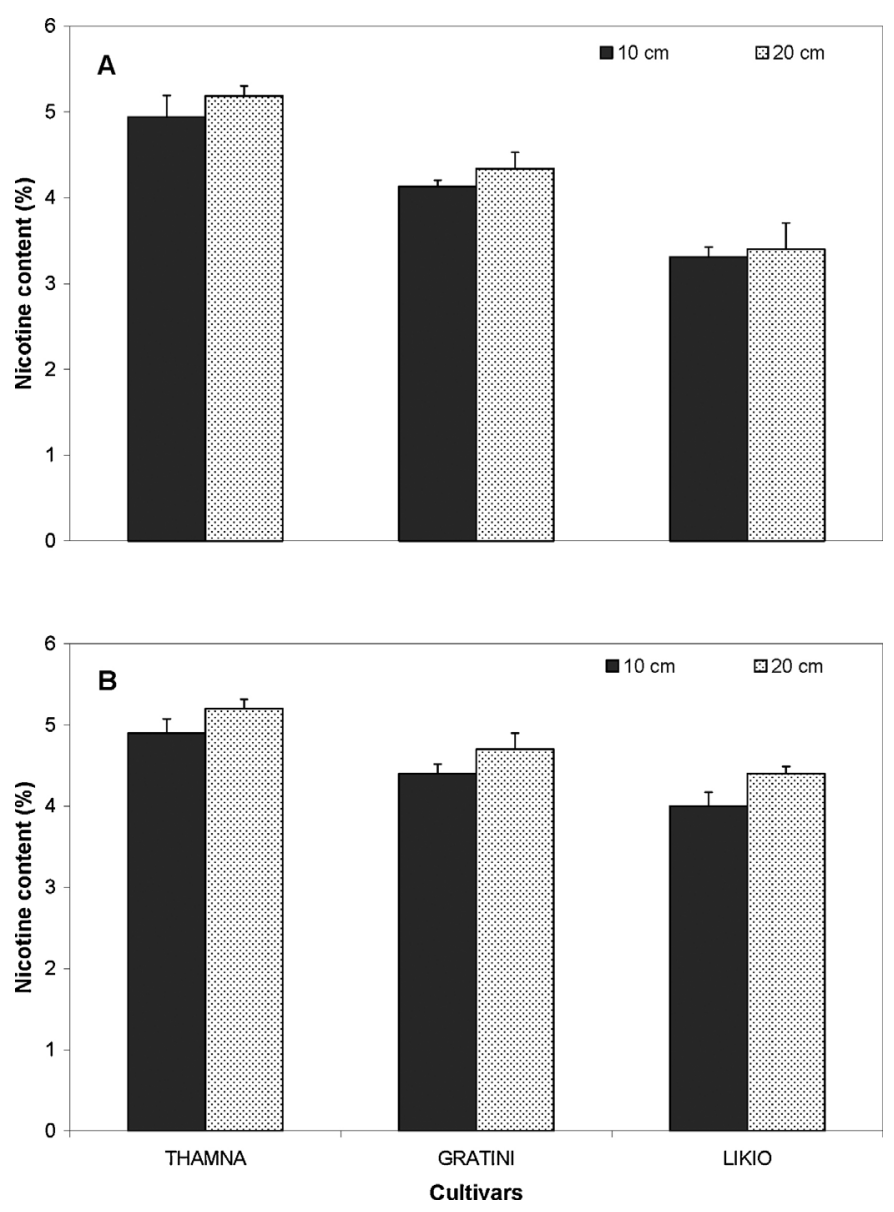

Fig. 4. Response of nicotine content for each cultivar to row spacing in (A) 2012 and (B) 2013. Bars denote standard errors of the means.

\subsection{Total yield}

Tobacco yield ranged from 1315 to 1920 and from 1545 to $2090 \mathrm{~kg} \mathrm{ha}^{-1}$, for the wider and narrower row spacing, respectively (Fig. 3). Row spacing of $10 \mathrm{~cm}$ resulted from 14 to $17 \%, 5$ to $35 \%$ and 9 to $11 \%$ higher yield than with the spacing of $20 \mathrm{~cm}$ for Thamna, Gratini and Likio, respectively. Moreover, there were some differences among the three cultivars with Likio showing the highest yield, from 27 to $39 \%$ and from 5 to $53 \%$ higher than the corresponding values for Thamna and Gratini, respectively. The wide range of the observed differences can be plausibly ascribed to the significant effect of row spacing on final yield $(P<0.001)$ and the significant interaction between year and cultivar $(P<0.05)$ as shown in Table 2 .

Results of the present study are in accordance with previous studies on burley and other oriental type cultivars (Lamprecht and Van der Merwe, 1984; Schlotzhauer et al., 1989 Sficas, 1970). Also, it has to be noted that especially in the case of narrow spacing, the yield of the studied cultivars was significantly higher not only from the corresponding values for wider spacing but also higher than other previously studied Oriental type tobacco cultivars (Delibacak et al., 2014).

\subsection{Quality parameters}

It is well known that tobacco quality is a complex combination of visual, physical and chemical characteristics of cured leaves (Mendell et al., 1984). Among them, traits such as nicotine content, sugars concentration and their ratio dramatically influence the quality of tobacco. Our results showed that nicotine content 

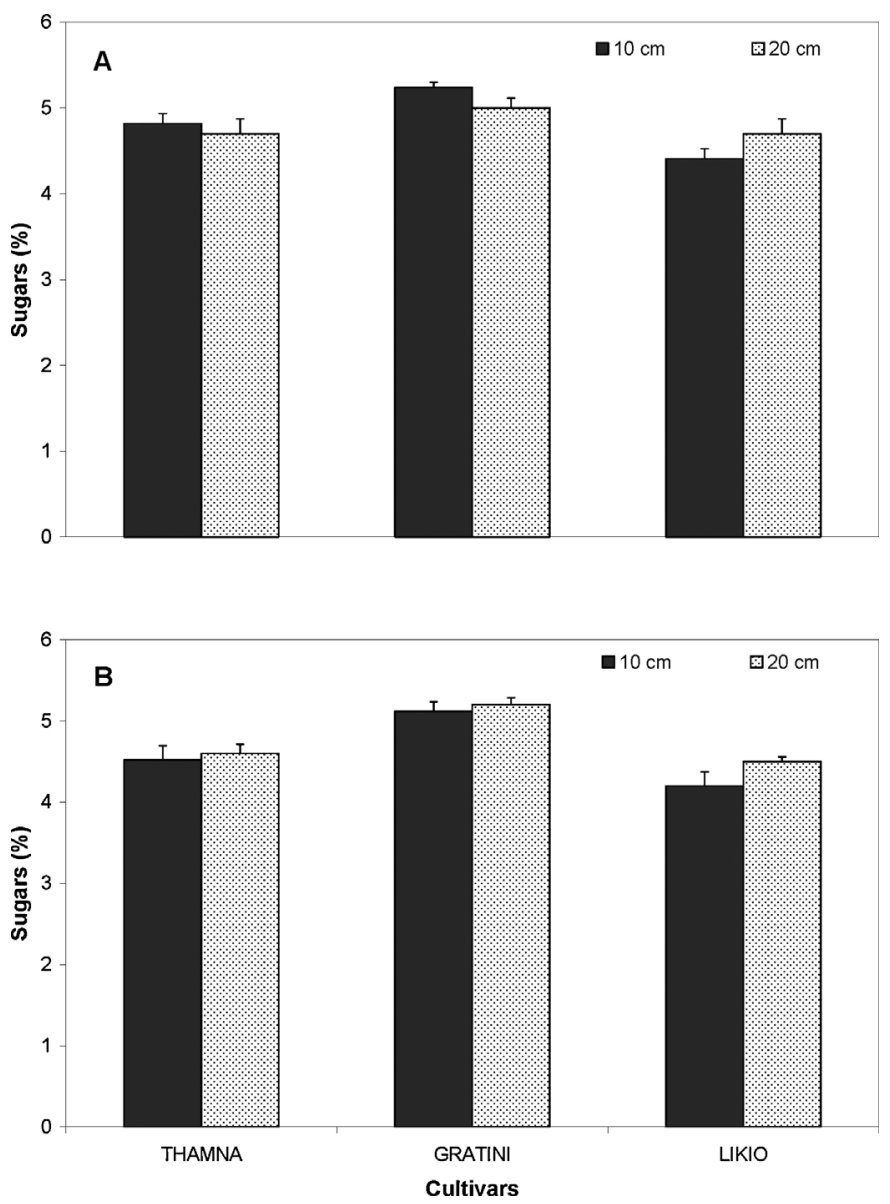

Fig. 5. Response of tobacco sugars for each cultivar to row spacing in (A) 2012 and (B) 2013. Bars denote standard errors of the means.

was affected by cultivar and row spacing and ranged between 3.40 and 5.19\%. In most cases, higher nicotine content was revealed for tobacco grown at wider spacing, since probably growth was higher in that case because of a lower plant density (Fig. 4). Thamna had a higher nicotine content compared to Gratini and Likio.

Reducing sugars concentrations is also an indicator of smoking quality (Weybrew et al., 1983). Among other factors, cultivar may substantially affect the levels of sugars (and not only nicotine) in tobacco leaf. In our case, Gratini was the cultivar with the highest sugar content in both row spacings and years (Fig. 5). However, none of the other factors (row spacing and year) had significant effect, confirming the important role of genotype on the quality parameters of tobacco (Xiao et al., 2007).

Regarding the ratio of sugars/nicotine, this was ranged between 0.885 and 1.415 in all cases, as shown in Table 3. Likio and Thamna had the highest and lowest values of this important index, respectively. Moreover, the effect of the year and its interaction with cultivars were also significant $(P<0.001$ and $P<0.01$, respectively). In general, it could be said that this low ratio of sugars/nicotine of our studies was due to high nicotine content combined with low content of dissolved sugars (Tso, 1990). High nicotine content without high availability of sugars is indicative of high strength of tobacco as previously described in several studies (Tso, 1990; Drachev, 2004). Chemical constituents of leaves in all types of tobacco are considered to be determinant factors for leaf quality. Considerable efforts have been directed at correlations between agronomic traits and chemical constituents (Legg et al., 1965; White et al., 1979), however there is still a clear lack of information particularly for sun-cured tobacco (Xiao et al., 2007).

\section{Conclusions}

The results of this study highlight the differences between three oriental tobacco cultivars regarding their growth, yield and quality at two row spacings. Wider row spacing (a common practice for Greek farmers) resulted in lower yield due to the lower number of tobacco plants compared with the narrow spacing. Narrow row spacing resulted to a reduction of nicotine content, probably because of a high competition among roots where alkaloids are synthesized. Narrower row spacing could be used in some cases for a higher production of tobacco of lower nicotine content, whenever this is desirable for blending purposes. Further studies should be conducted on the evaluation of the effects of several agronomic practices on growth, yield and quality especially for the less-studied and high-promising cultivars of oriental tobacco.

\section{Acknowledgements}

Authors would like to thank the Co-operative Union of Tobacco producers of Greece (SEKE S.A.) for the seed offer and part of the chemical analyses and Christos Zisoudis, Eirini Vlachou and Eleni Vulgari for their invaluable help with field and experimental activities.

\section{References}

Akehurst, B.C., 1968. Tobacco. Longman, London, England and New York, New York. Bilalis, D., Karkanis, A., Efthimiadou, A., Konstantas, A., Triantafyllidis, V., 2009. Effects of irrigation system and green manure on yield and nicotine content of Virginia (flue-cured) organic tobacco (Nicotiana tabaccum), under mediterranean conditions. Ind. Crops Prod. 29, 388-394.

Bouyoucos, G.J., 1962. Hydrometer method improved for making particle size analyses of soils. Agron. J. 54, 464-465.

Bukan, M., Budimir, A., Boic, M., Sarcevic, H., Kozumplik, V., 2010. Effect of within-row spacing on agronomic and morphological characteristics of the flue-cured tobacco cultivars. Agric. Conspec. Sci. 75, 27-31.

Campbell, J.S., Chaplin, J.F., Boyette, D.M., Campbell, C.R., Crawford, C.B., 1982. Effect of plant spacings, topping height, nitrogen rates and varieties of tobacco on nicotine yield and concentration. Tob. Inter. 184, 72-75.

Chaplin, J.F., Ford, Z.T., Pitner, J.B., Currin, R.E., 1968. Effect of row and within row spacings on yield and quality of flue-cured tobacco. Agron. J 60, 314-316.

Collins, W.K., Hawks, S.N., Kitrell, B.U., 1969. Effects of plant spacing and height of topping at two nitrogen rates on some agronomic-economic characteristics on bright tobacco. Tob. Sci. 13, 150-152.

CORESTA, 1994a. CORESTA recommended method no. 35. Determination of total alkaloids (as nicotine) in tobacco by continuous flow analysis. http://www. coresta.org/Recommended_Methods/CRM_35pdf

CORESTA, 1994b. CORESTA recommended method no. 38. Determination of reducing carbohydrates in tobacco by continuous flow analysis. http://www. coresta.org/Recommended_Methods/CRM_38pdf

Delibacak, S., Ongun, A.R., Ekren, S., 2014. Influence of soil properties on yield and quality of tobacco plant in Akhisar region of Turkey. Eurasian J. Soil Sci. 3, 286-292.

Drachev, D., 2004. Investigation on technological indexes of large leaf tobaccos produced in different areas in Bulgaria. Biotechnol. Biotechnol. Equip. 18, 75-81.

Lamprecht, M.P., Van der Merwe, W.J.C., 1984. Reaction of oriental tobacco to spacing and topping treatments at three levels of nitrogenous fertilizer application. S. Afr. J. Plant Soil 1, 132-134.

Legg, P.D., Matzinger, D.F., Mann, T.J., 1965. Genetic variation and covariation in a Nicotiana tabacum L. synthetic two generations after synthesis. Crop Sci. 5, 30-33.

Lolas, P.C., Galopoulos, A., Sficas, A.G., 1983. Growth characteristics of oriental tobacco as affected by cultivar and type. Agron. J. 76, 917-921.

Mendell, S., Bourlas, E.C., DeBardeleben, M.Z., 1984. Factors influencing tobacco leaf quality: an investigation of the literature. Beitr. Tabakforsh. 12, 153-167.

Rezitis, A.N., Brown, A.B., 1999. Pass-through of exchange rates and tariffs in Greek-US tobacco trade. Agr. Econ. 21, 269-277.

Sficas, A.G., 1970. Irrigation experiments on oriental tobacco. Beitr. Tabakforsh. 5, 259-261.

TIC (Tobacco Institute of Greece), 1996. Guide of Tobacco Cultivation. In: Oriental, Virginia. Burley. Drama. Art of Text Publisher, 191.

Travlos, I.S., Kanatas, P.J., Tsioros, S., Papastylianou, P., Papatheohari, Y., Bilalis, D., 2014. Green manure and pendimethalin impact on oriental sun-cured tobacco. Agron. J. 106, 1225-1230.

Tso, T.C., 1990. Production, Physiology and Biochemistry of Tobacco Plant. Ideals Inc., Beltsville, Maryland USA. 
Wakley, A., Black, I.A., 1934. An examination of the Degtiareff methods for determining soil organic matter and a proposed modification of chromic acid titration method. Soil Sci. 37, 29-38.

Weybrew, J.A., Wan Ismail, W.A., Long, R.C., 1983. The cultural management of flue-cured tobacco quality. Tob. Sci. 27, 56-61.

White, F.H., Pandeya, R.S., Dirks, V.A., 1979. Correlation studies among and between agronomic, chemical, physical and smoke characteristics in flue-cured tobacco (Nicotiana tabacum L.). Can. J. Plant Sci. 59, 111-120.
Xiao, B.G., Zhu, J., Lu, X.P., Bai, Y.F., Li, Y.P., 2007. Analysis on genetic contribution of agronomic traits to total sugar in fue-cured tobacco (Nicotiana tabacum L.). Field Crops Res. 102, 98-103. 